\title{
O DEPÓSITO METÁLICO DA BANDEIRA, VIANA DO CASTELO (NORTE DE PORTUGAL) NO CONTEXTO DOS DEPÓSITOS DO BRONZE MÉDIO DO CURSO INFERIOR DA BACIA DO LIMA
}

\author{
JoÃo Oliveira Fernandes ${ }^{(1)}$, Ana M.S. BetTencourT(2), \\ Beatriz Comendador ReY(3) \& M. Isabel CaEtano Alves(4)
}

Resumo:

\begin{abstract}
Este texto tem como objetivo dar a conhecer o depósito de um machado de tipo Bujões / Barcelos encontrado no lugar da Bandeira, Viana do Castelo, no seu micro-contexto de achado; as suas características técnicas e morfológicas genéricas e a sua inter-relação espacial com os restantes depósitos deste período no curso inferior do rio Lima.

Apesar de ter sido realizado apenas um estudo macroscópico, o que inviabiliza considerações precisas sobre processos arqueometalúrgicos, a sua localização, num terraço nas proximidades da ribeira de Fornelos / / São Vicente, em área profundamente irrigada de um patamar inferior da Serra de Santa Luzia, permite considerar que se vincularia com um lugar liminar entre a serra e as águas, mas também, com um lugar de passagem entre estes dois meios.

No âmbito do curso inferior do rio Lima, os raros machados deste tipo atribuíveis ao Bronze Médio foram depositados em contextos diversificados se analisados à micro-escala. Estes associam-se a afloramentos, a mina ou a um terraço fluvial (?). No entanto, a uma média escala de análise, associam-se preferencialmente a locais impressivos e liminares entre a terra e as águas, a lugares de passagem e a espaços onde existiria estanho de aluvião, segundo análises sedimentológicas realizadas em diversos pontos do rio Lima. Tais caraterísticas abre-nos perspetivas interpretativas sobre o valor social e religioso destes artefactos, sobre as ações que culminaram na sua deposição e sobre os lugares escolhidos para as deposições.
\end{abstract}

Palavras-chave: NW da Península Ibérica; Machados de tipo Bujões/Barcelos; Depósitos; Lugares liminares; Lugares de passagem, partida e chegada; Lugares de estanho; Lugares de significação mágico-religiosa.

Abstract:

The Bandeira hoard, Viana do Castelo (North of Portugal) in the context of Midle Bronze Age hoards of the lower basin of the Lima River

The purpose of this paper is to publicize the deposit of a flat axe of Bujões / Barcelos type, found in place of Bandeira, Viana do Castelo; its context of discovery; its formal and technical characteristics and their spatial interrelation with the estuary of the Lima River.

Although it was performed only a macroscopic study, making it impossible precise considerations on archaeometallurgical processes, its location allows us to consider that it binds to a liminal place between the mountains and the waters, but also with a crossing point between these two natural spaces.

Within the lower reaches of the Lima River, the axes of this type were deposited in different contexts, if we take into account the microscale analysis. These artefacts were associated with fluvial terraces (?), mining contexts and settings with granite outcrops. However, in the average scale of analysis, these are preferentially associated with impressive and liminal places between the land and waters, crossing places and spaces where alluvial tin exist, according to sedimentological analysis carried out in several sections of the Lima River.

These features open the interpretive perspectives on the value of these social and religious artefacts, on the actions that culminated in his deposition and the places chosen for deposition.

Key-words: NW of Iberian Peninsula; Flat axe of Bujões/Barcelos type; Hoard; Liminal places; Passage, departure and arrival places; Places with tin; Magical religious places.

(1) Arqueólogo. Licenciado em História, variante de Arqueologia pela Faculdade de Letras da Universidade de Coimbra. jasof@sapo.pt.

(2) Departamento de História da Universidade do Minho, Instituto de Ciências Sociais, Campus de Gualtar, 4710-057, Braga, Portugal. Investigadora do Centro de Investigação Transdisciplinar Cultura, Espaço e Memória - CITCEM, financiado por Fundos Nacionais através da FCT - Fundação para a Ciência e a Tecnologia no âmbito do projecto PEst-OE/HIS/UI4059/2011. anabett@uaum.uminho.pt.

(3) Departamento de História, Arte e Geografía da Universidade de Vigo, Campus de As Lagoas, 32004 Ourense, España. Investigadora do Grupo GEAAT da Universidade de Vigo. beacomendador@uvigo.es

(4) Departamento de Ciências da Terra da Universidade do Minho. Campus de Gualtar, 4710-057 Braga, Portugal. Investigadora do CGUP/UM e do CCT/UM. icaetano@dct.uminho.pt 


\section{Condições e LocalizaÇão do ACHado}

O machado da Bandeira foi encontrado em 1967 na propriedade da $\mathrm{Sr}^{\mathrm{a}}{ }^{\mathrm{D}} \mathrm{D}$. Isaura Alves Barbosa Mendes, então residente na rua da Bandeira,.$^{\circ}$ 623, freguesia de Santa Maria Maior, em Viana do Castelo. A casa dessa propriedade ainda hoje subsiste e situa-se no tramo nascente da rua, o mais afastado do centro histórico de Viana e o mais tardiamente edificado. A rua da Bandeira, cujo nome advirá da proximidade à Gafaria de São Vicente, constitui um extenso arruamento delineado, no seu trecho poente, na segunda metade de Quatrocentos e implementado ao longo do período Quinhentista e seguintes. Estendia-se pelos arrabaldes a nascente da então vila de Viana da Foz do Lima, extremando com a freguesia da Meadela na ribeira de Fornelos / São Vicente, tendo-se definido ao longo do tempo como um importante eixo viário de comunicação e comércio (FERNANDES 1992).

O local do achado inseria-se nos derradeiros terrenos de uma pequena quinta murada, gradualmente ocupada na sua área original pelo crescimento urbano, viário e infraestrutural implementado na zona oriental da cidade de Viana do Castelo, ao longo do século XX. As coordenadas decimais deste local no sistema WGS84 são: 41.702098 e -8.819619; a c. 10 m de altitude (Fig. 1). As coordenadas geográficas são: $41^{\circ} 42^{\prime} 7.8^{\prime}$ ' N e 8 49' $10.38^{\prime}$ ' W.

Segundo informações da Sr. ${ }^{a}$ D. Isaura Maria Mendes Cerqueira ${ }^{1}$ e do Sr. Fernando Manuel Gomes Cerqueira, filha e genro, respectivamente, da referida senhora e atuais proprietários do local onde se verificou o achado, o "ferrinho", designação então dada à peça, apareceu na terra resultante da abertura de uma vala para o plantio de um pessegueiro de médio porte, acomodado em matéria orgânica e feno, o que implicou uma abertura no solo de c. de $2 \mathrm{~m}$ de profundidade. Durante esse processo "ressoou um tilintar metálico nalguns seixos rolados", que veio a revelar-se o exemplar do machado em estudo. Segundo os nossos informantes, a peça metálica surgiu na "terra boa e fértil" que caracteriza aquele subsolo, experienciado pelos anos de lavradio ali exercidos, onde não foram encontrados quaisquer indícios de existirem rochas graníticas e rochas metamórficas, em estado de serem identificáveis como tal no referido subsolo. Assim, aquando do seu achado, o artefacto metálico estava depositado num nível de terra de coloração castanha escura a negra que continha alguns seixos rolados e onde não foi presenciada a existência de recipientes ou fragmentos de cerâmica associados, nem mesmo posteriormente, durante outros trabalhos agrícolas realizados no terreno. Este nível de terra assentava no substrato saibroso.

Conhecido desde 2004 por um dos autores (JOF) e referenciado sumariamente por outro, aquando da publicação de um trabalho relacionado com a pré-história da fachada atlântica de entre o Lima e o Minho (BETTENCOURT 2009a), tornava-se importante o seu estudo e contextualização, por se tratar de um artefacto metálico relativamente raro e aparentemente in situ.

A peça encontra-se na posse do casal Cerqueira.

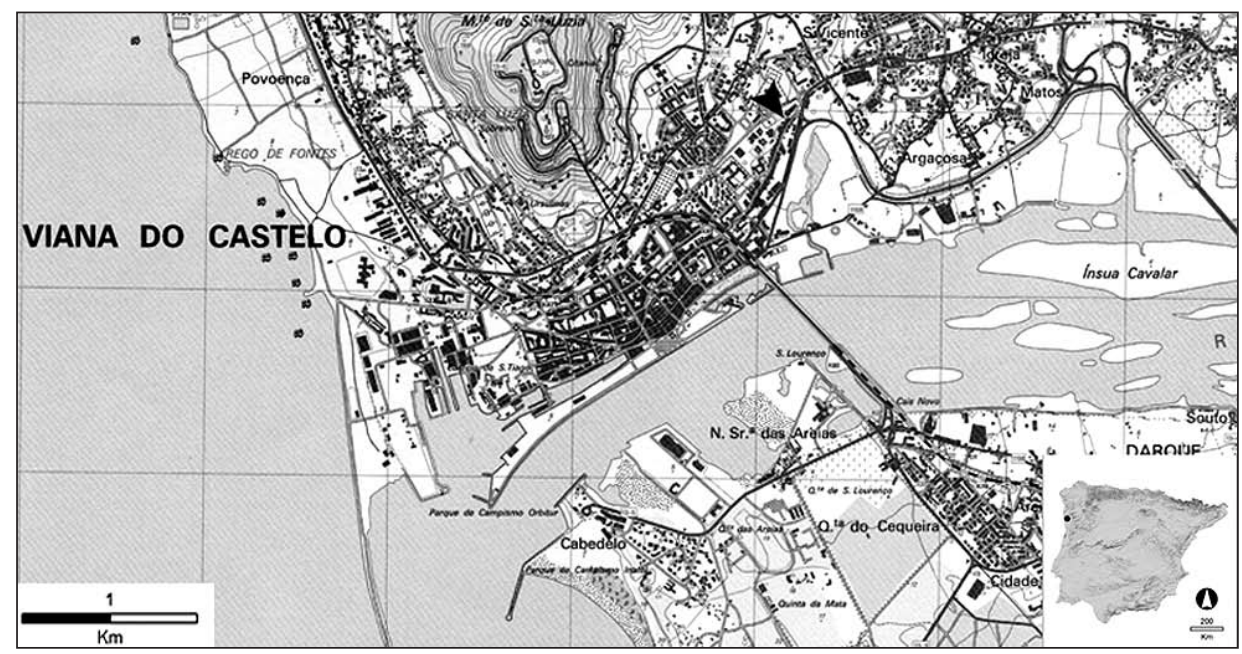

Fig. 1. Localização do achado arqueológico da Bandeira na Carta Militar de Portugal, folha 40, na escala 1:25 000 (IGEOE 1997).

Fig. 1. Location of the Bandeira hoard in the Military Map of Portugal, n. ${ }^{\circ} 40$, scale: 1:25 000 (IGEOE 1997). 


\section{Contexto Físico}

Em termos geológicos o local do achado fica nos depósitos de praias antigas e de terraços fluviais cobrindo o substrato rochoso, constituído, na área, por rochas graníticas e pelos metassedimentos do Câmbrico indiferenciado encaixantes - a Formação Desejosa (PEREIRA 1989, 1992).

Em termos geomorfológicos corresponde a uma plataforma na base da vertente Sudeste da serra de Santa Luzia, sem afloramentos rochosos à superfície e nas imediações de uma área de confluência fluvial, nas proximidades do ponto onde, a Sudeste, a ribeira de Fornelos / São Vicente desagua no rio Lima. Trata-se de uma zona que recebe as águas de drenagem dos flancos sobranceiros da serra, o que se atesta pela presença de um curso de água a menos de $100 \mathrm{~m}$ para Norte do local de achado, tributário da referida ribeira que corre, a cerca de $500 \mathrm{~m}$ para Nor-Nordeste, seguindo uma pendência para Su-Sudeste (cf. fig. 1).

Assume-se também como espaço de ambiência fluvial, contíguo ao estuário limiano, onde nos terrenos inferiores à Bandeira, pelos lados Sudeste e Sul, radicado entre a Papanata e a Argaçosa, se encontra uma área de "caldeira", designação popular para o sapal que margina o rio Lima, neste local. Formada como receptáculo dos cursos de água advindos a montante e pelas oscilações das águas do rio Lima, situa-se hoje numa parte do Parque da Cidade. Nos primórdios do século XIX aí se instalaram as denominadas Azenhas de D. Prior, albergando um pequeno complexo hidráulico consubstanciado num moinho de maré para a moagem de cereais, aproveitando a enchente e a vazante das águas do rio Lima.

O campo visual do lugar do achado permitiria abarcar uma envolvente delineada pelos contornos altimétricos das elevações em redor. Num primeiro plano, para Norte e Noroeste, cerceado pelas vertentes e pelo topo da Serra de Santa Luzia, o campo de visão era fechado e limitado; a Nordeste, ocupando o último plano, o maciço granítico da Serra de Arga impor-se-ia; para nascente, vislumbrar-se-ia o monte de São Silvestre e, tutelando o espaço a sul da banda limiana, avistar-se-ia o monte do Alto do Galeão, pelo que se verificaria a visualização do Lima no quadrante sul. Este corredor fluvial desemboca no mar, a Sudoeste, pelo que é possível que este se avistasse, na linha do horizonte.

\section{Descrição da PeÇa}

\subsection{Morfológica}

O artefacto metálico encontrado na Bandeira é um machado plano de contorno trapezoidal, com as faces laterais côncavas, talão retangular, gume desenvolvido e seção retangular. Nele são observáveis pequenos sulcos, transversais à superfície da peça, e uma zona ligeiramente deprimida num dos lados, perto do talão. Apresenta patina de carbonatos aparentemente estável. A superfície aparenta ter sido polida embora a zona do talão parece ter sofrido polimento recente. $\mathrm{O}$ gume contém fraturas que podem estar relacionadas com processos posdeposicionais de conservação.

Do ponto de vista tipológico poderia enquadrar-se no conjunto de machados planos de gumes desenvolvidos, entre os que se incluem os de tipo Barcelos, definidos por E. MacWhite (1951), cuja característica principal é o facto de o gume, profundamente alargado, ter uma forma semicircular. De notar, no entanto, que P. Harbison (1967: 12) assinalou a dificuldade em distinguir alguns destes exemplares dos de tipo Bujões, o que indica não existir uma grande diferença tipológica ou cronológica entre eles.

Mede de comprimento máximo $167 \mathrm{~mm}$; de largura máxima $85 \mathrm{~mm}$; de espessura máxima $11 \mathrm{~mm}$ e de espessura do talão $7 \mathrm{~mm}$. Pesa aproximadamente $600 \mathrm{gr}^{2}$ (Figs. 2 e 3).

As suas dimensões e peso aproximado correspondem à média observada para este conjunto de machados no Norte de Portugal e na Galiza, à volta dos $180 \mathrm{~mm}$ de altura e de $500 \mathrm{gr}$ de peso (COMENDADOR 1999: Tabla 6 e nota 2).

\subsection{Tecnológica}

De uma forma geral, do ponto de vista tecnológico o processo de vazamento proporcionou uma peça bem calibrada. Não se observam rebarbas nem sinais de união das valvas do molde, pelo que, após o processo de fundição, terá sido acabada através do recurso a polimento. O gume parece ter sido definido mediante deformação plástica, hipótese que só poderá confirmar-se através da realização de uma micrografia.

A maior singularidade deste artefacto é a existência de uma série de pequenos "buracos" numa das suas faces, com profundidades superiores a $2 \mathrm{~mm}$ e

Foi pesado numa balança analógica, com capacidade de $5 \mathrm{Kg}$ e sensibilidade de $20 \mathrm{~g}$. 


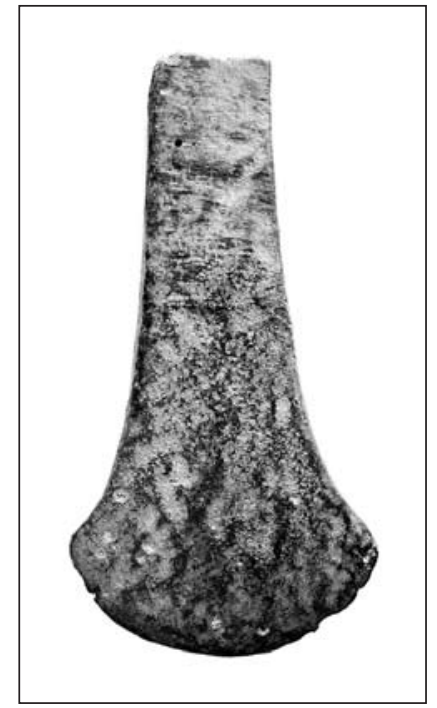

Fig. 2. Fotografia geral do machado (As dimensões são dadas no texto).

Fig. 2. Flat axe of Bujões / Barcelos type found in Bandeira.

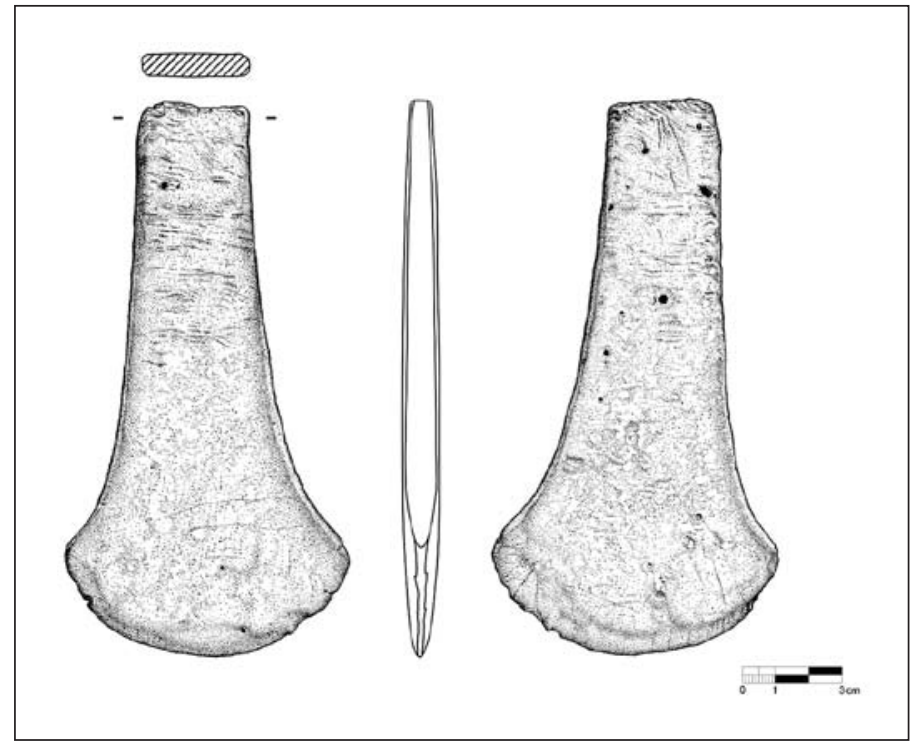

Fig. 3. Desenho do machado de tipo Bujões / Barcelos (desenho realizado por Vitor Vazquez Collazo).

Fig. 3. Draw of the flat axe of Bujões / Barcelos type found in Bandeira (drawing by Vitor Vazquez Collazo). com diferentes secções. Dado o seu aspecto e distribuição irregular, pensamos serem vácuolos resultantes da presença de gases durante o processo de fundição (Fig. 2). Alguns apresentam uma corrosão mais acentuada com presença de cloretos na zona mais deprimida.

Desconhecemos a composição química deste machado mas, tendo em conta o exemplo de peças metálicas semelhantes, trata-se provavelmente de um bronze binário $(\mathrm{Cu}+\mathrm{Sn})$ com percentagens bastante regulares à volta da mistura eutética $(90 \% \mathrm{Cu}-10 \%$ Sn e impurezas) (COMENDADOR 1999: Tabla 5).

Neste sentido, procuraremos realizar uma análise compositiva (como por exemplo Fluorescência de Raios X) para determinar a composição geral, assim como uma micrografia para conhecer os processos mecânicos e/ou térmicos a que foi submetido.

Como medida preventiva seria importante estabilizar a peça.

\section{O Depósito Metálico da Bandeira no Contexto local e no Contexto do CURSO INFERIOR DO LIMA}

As características do local do achado e as boas condições de conservação do machado fazem-nos crer que este teria sido depositado intencionalmente no subsolo, na margem de contextos aquáticos, durante o Bronze Médio ${ }^{3}$. Corresponderia, assim, a uma deposição intencional, ou seja, à materialização de determinados atos sociais que implicaram a amortização simbólica de artefactos metálicos.

O lugar escolhido para o cerimonial foi a base da serra de Santa Luzia, mais precisamente os depósitos de um terraço, perto da foz da ribeira de Fornelos / / S. Vicente, afluente do rio Lima, local natural de passagem entre as terras baixas e as plataformas mais altas da serra mas, também, de acesso a uma área onde, até aos inícios do séc. XX, se apanhava a barca para fazer a travessia do rio Lima ${ }^{4}$ (Figs. 1 e 4).

3 Apesar de inseríveis genericamente neste período a cronologia precisa destes machados é desconhecida no Noroeste Peninsular, embora se saiba que, no segundo quartel do II milénio AC, já se fabricavam peças em bronze como indiciam os dados da Sola IIb, em Braga, povoado onde também apareceu um discutível molde deste tipo de machados (BETTENCOURT 1999, 2000). A produção de machados de tipo Bujões / Barcelos em contextos do Bronze Médio está documentada no povoado da Cimalha, Felgueiras, onde um fragmento de molde duplo (BETTENCOURT 2009b) se associa a um acervo cerâmico similar ao existente no povoado da Sola, como pudemos constatar graças à amabilidade de Andreia Arezes e de Francisco Queiroga. Também na Fraga dos Corvos, em Macedo de Cavaleiros, apareceu um molde deste tipo de machados em associação com cerâmicas de tipo Cogeces ou Protocogotas, segundo informação pessoal de João Carlos de Senna-Martinez. Na Galiza registaram-se, igualmente, indícios da produção destes artefactos embora sem contexto cronológico muito preciso, como é o caso do de Monte das Carballas, Guillade, Ponteareas, em Pontevedra e de Erosa, A Gudiña, em Ourense (COMENDADOR 1999).

4 Informação obtida por AMSB no âmbito do projeto Celebração da Cultura Costeira - CCC, financiado pelo Mecanismo Financeiro do Espaço Económico Europeu / EEA Grants, Noruega e co-financiado pela Câmara Municipal de Sines e Mútua de Pescadores. 


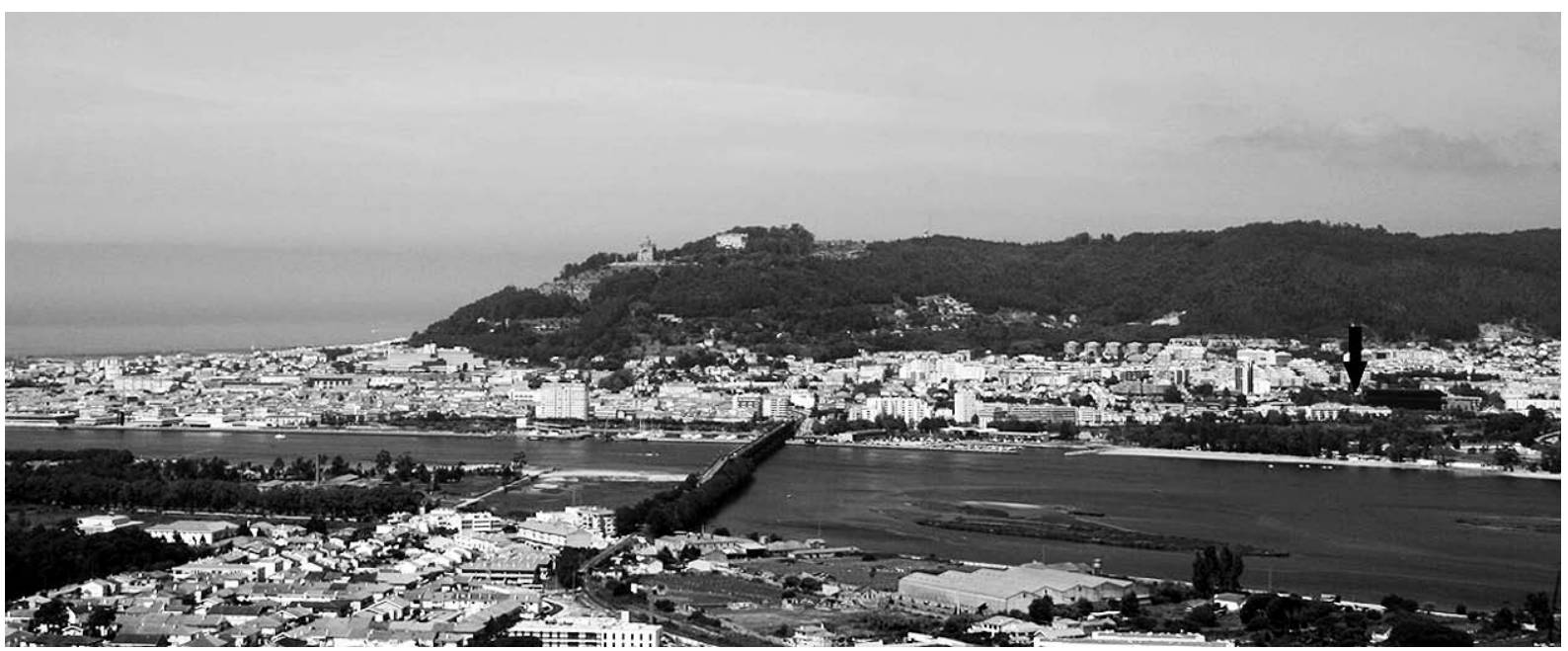

Fig. 4. Vista geral do estuário do rio Lima com indicação da área do achado do depósito metálico.

Fig. 4. Overview of the Lima River estuary with the location of where the metallic hoard was discovered.

Tal parece indiciar a importância social e simbólica de lugares liminares ou, se quisermos, de chegada e de partida, entre a terra e as águas, situação que se crê recorrente neste locus ao longo da Idade do Bronze pois aí teriam ocorrido novos atos de deposição no Bronze Final ${ }^{5}$. De notar que o simbolismo do estuário do Lima e da extremidade da serra de Santa Luzia está bem patente em épocas posteriores (BETTENCOURT 2009a).

Ignoramos outros dados referentes ao Bronze Médio nas proximidades embora se conheçam machados de tipo Bujões / Barcelos provenientes do curso inferior da bacia do Lima. Referimo-nos ao da Folgadoura, Vilar de Murtede, em Viana do Castelo, procedente do enchimento de uma antiga mina de estanho (ZBYSZEWSKI \& FERREIRA 1955) e a, pelo menos, um do monte de Santo Ovídio, Arcozelo, Ponte de Lima, cujo micro-contexto se desconhece (RUSSEL CORTEZ 1946), embora o local possua abundantes e impressionantes formas graníticas.

Apesar da amostragem reduzida e dos lugares escolhidos para estas deposições indiciarem diversidade à micro-escala, à média escala de análise denotam-se regularidades dignas de nota: todos foram encontrados em loci relacionados com as águas, no que R. Vilaça (2007) denomina de "depósitos de margem"; em lugares de passagem ou de partida/chegada; em associação visual com relevos impressivos e nas proximidades de áreas ricas em estanho de mineralizações primárias e/ou em aluvião. Senão vejamos: o monte de Santo Ovídio, na extremidade sul da serra de Antelas, de configuração cónica e

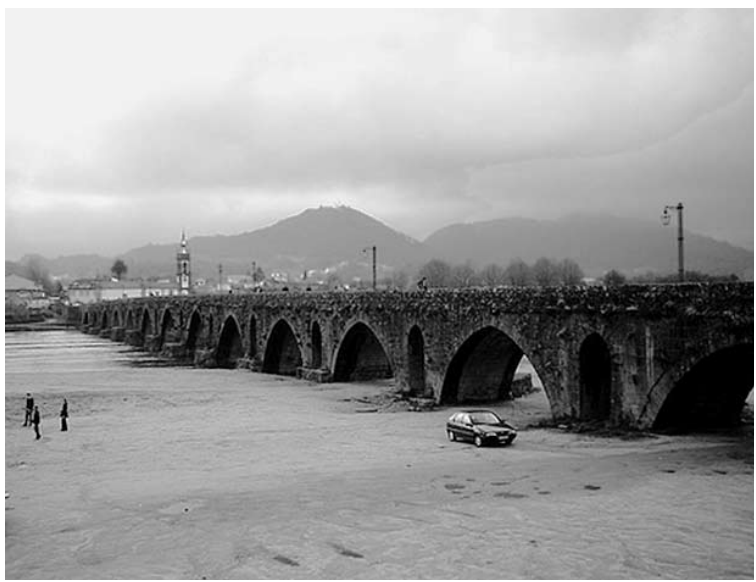

Fig. 5. Monte de Santo Ovído e ponte medieval sobre o Lima em frente à vila de Ponte de Lima (Fot. retirada de vila--verde.blogspot.com).

Fig. 5. Location of the Santo Ovídio Mount and medieval bridge over the Lima River, opposite Ponte de Lima (after vila-verde.blogspot.com).

imponente, fica sobranceiro ao rio Lima, em frente a Ponte de Lima, área natural de passagem entre as duas margens (Fig. 5). Fica também, na confluência dos rios Estorãos, a oeste, e do rio Labruja, a este, ambos com cassiterite nas aluviões e nos respectivos depósitos de terraço (Alves 1995; Alves et al. 2003). A mina da Folgadoura, rica em cassiterite, ouro e volfrâmio (CMN 1942a), fica no monte residual do Folgadoiro, destacado nos vales de Nogueira e do Seixo, e profícuo em mineralizações primárias de estanho e de ouro (LiMA 2006). O monte de Fol-

Há notícia do aparecimento de um depósito metálico composto por machados de talão, nas imediações da Bandeira, que se pretende estudar no âmbito do projeto ENARDAS (PTDC / HIS-ARQ / 112983 / 2009). 


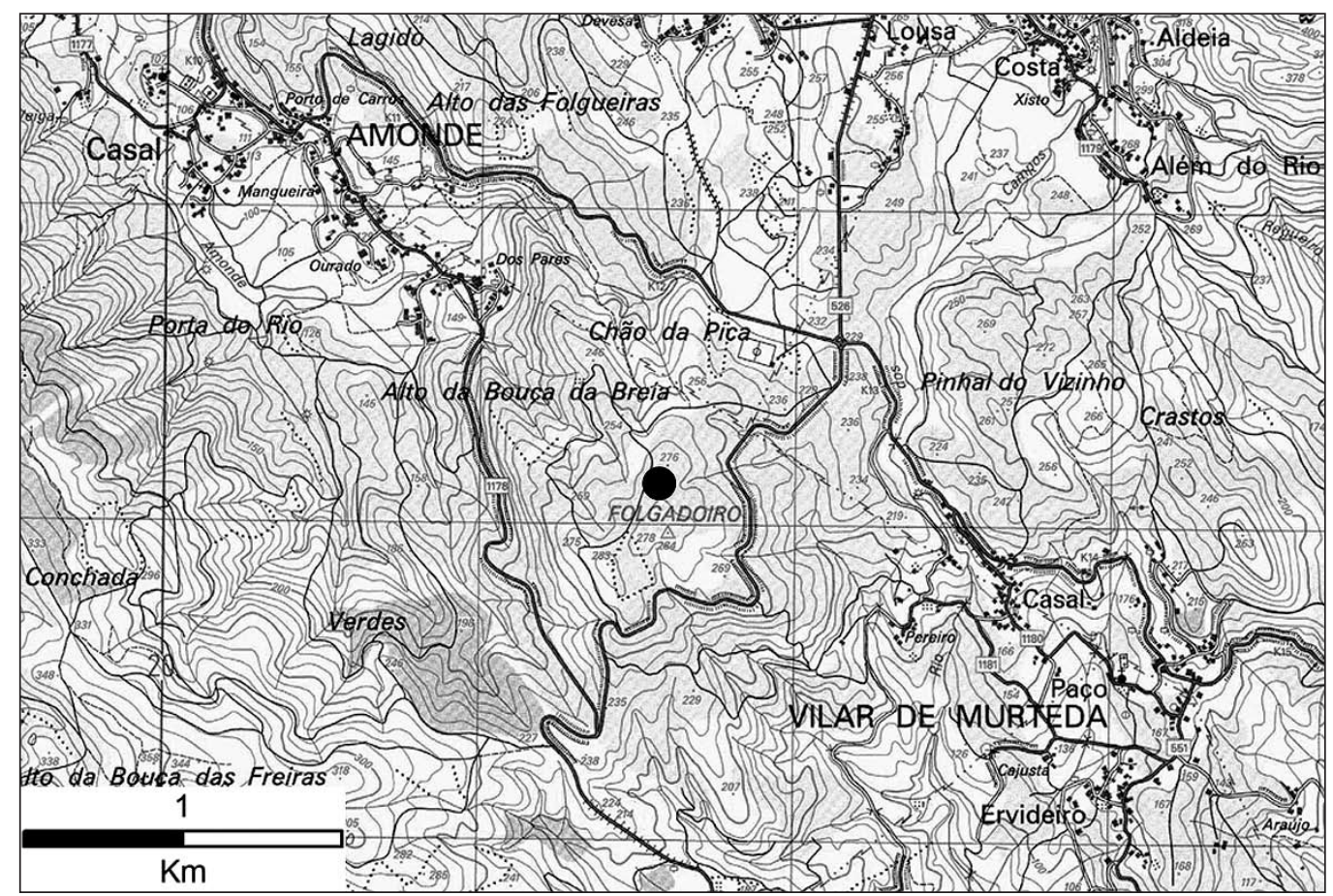

Fig. 6. Localização do Monte do Folgadoiro na Carta Militar de Portugal, folha 27, na escala 1:25 000 (IGEOE 1997).

Fig. 6. Location of the Folgadoiro Mound in the Military Map of Portugal, n. ${ }^{\circ} 27$, scale: 1:25 000 (IGEOE 1997).

gadoiro constitui, também, uma "portela" entre as bacias de drenagem dos rios Âncora e Lima pois aí nascem inúmeros afluentes do ribeiro de Amonde e do rio do Seixo (Fig. 6), ambos com areias ricas em estanho de aluvião e tributários daqueles rios respetivamente. Saliente-se que a cassiterite ocorre nas aluviões e nos depósitos de terraços fluviais antigos de afluentes do rio Lima existentes em Lanheses, Vila Mou e Torre (Alves 1995) sendo, portanto, muito frequente na margem norte do rio, naquelas áreas, mas existindo também, nas aluviões do estuário do Lima (ALVES 1996) pelo que não seria impossível a sua presença à foz do ribeiro de Fornelos / S. Vicente.

Mesmo tendo em conta que no Bronze Médio, ou seja, a partir de c. de $3500 \mathrm{BP}$, o espelho de água do curso inferior da bacia do Lima seria diferente do atual, provavelmente menos amplo e mais encaixado, e que a foz estaria deslocada para a Oeste, segundo estudos elaborados no estuário deste rio e nas aluviões do rio Estorãos (Alves \& ALVEs 1993; ALVES 1995; Alves 1996; Alves et al. 2003), o que se traduziria, à micro-escala, numa menor proximidade dos cenários de deposição de artefactos metálicos aos meios aquáticos, estes estariam sempre omnipresentes numa relação visual de proximidade.

Assim sendo, a disposição espacial de todos estes depósitos parece revelar a importância simbólica de determinados lugares liminares de passagem, partida e ou chegada, ricos em estanho e próximos de água, assim como da "dádiva" de artefactos metálicos no interior da terra, num conjunto de ações e de interações com o meio cujos significados cremos de caráter mágico-religioso associados à importância das propriedades ou dos espíritos que os diferentes elementos do mundo físico teriam para as populações do Bronze Médio.

\section{AgRAdecimentos}

Este trabalho foi realizado no âmbito dos projectos Metalurgia Primitiva no Território Português - EARLYMETAL (PTDC / HIS-ARQ / 110442 / 2008), financiado pela Fundação para a Ciência e a Tecnologia (FCT) e Espaços naturais, arquitecturas, arte rupestre e deposições na pré-história recente da fachada ocidental do centro-norte português: das acções aos significados - ENARDAS (PTDC / HIS-ARQ / 112983 / 2009), financiado pelo Programa Operacional Temático Factores de Competitividade (COMPETE) e comparticipados pelo Fundo Comunitário Europeu FEDER.

Os autores agradecem à Sr. ${ }^{a}$ D. Isaura Maria Mendes Cerqueira e ao Sr. Fernando Manuel Gomes Cerqueira a possibilidade de estudar o machado e os esclarecimentos gentilmente cedidos, a Andreia Arezes, a Francisco Queiroga e a José Carlos de Senna Martinez as informações prestadas e a Vitor Vazquez Collazo o desenho do machado. 


\section{BIBLIOGRAFIA}

Alves, A.M.C. 1996. Causas e processos da dinâmica sedimentar na evolução actual do litoral do Alto Minho. Braga: Universidade do Minho (Tese Doutoramento).

Alves, M.I.C. 1995. Materiais Plio-quaternários do Alto Minho. Produtos de Meteorização e Depósitos Fluviais na Bacia do rio Lima e região de Alvarães. Braga: Universidade do Minho (Tese de Doutoramento).

Alves, M.I.C. \& Alves, A.M.C. 1993. Os sapais do rio Lima (caracterização mineralógico-textural dos sedimentos). El Cuaternário en Espana y Portugal. Vol. I. Madrid: Instituto Tecnologico Geominero de Espana: 181-189.

Alves, A.C.; Alves, M.I.C.; PEREIRA, D. \& GONCALVES, M. 2003. Aluviões de Bertiandos (Ponte de Lima): estudo preliminar para a reconstituição ambiental holocénica no Entre Douro e Minho. Ciências da Terra, n. ${ }^{\circ}$ especial 5: 2 e CD-ROM: A1-A4

BetTenCOURT, A.M.S. 1999. A paisagem e o homem na bacia do Cávado durante o II e o I milénios AC. 5 vols. Braga: Universidade do Minho (Tese de Doutoramento).

Bettencourt, A.M.S. 2000. O povoado da Idade do Bronze da Sola, Braga, Norte de Portugal. Cadernos de Arqueologia - Monografias 9. Braga: Unidade de Arqueologia da Universidade do Minho.

BetTenCourt, A.M.S. 2009a. Entre os montes e as águas: ensaio sobre a percepção dos limites na pré-história da faixa costeira entre o Minho e o Lima (NW português). In A.M.S. Bettencourt \& L.B. Alves (eds.) Dos montes, das pedras e das águas. Formas de interacção com o espaço natural da pré-história à actualidade. Braga: Centro de Investigação Transdisciplinar de Cultura, Espaço e Memória - CITCEM e Associação Portuguesa para o Estudo do Quaternário - APEQ: 131-162.

Bettencourt, A.M.S. 2009b. A Pré-História do Minho: do Neolítico à Idade do Bronze. In P. PEREIRA (coord.) Minho. Traços de Identidade. Braga: Conselho Cultural da Universidade do Minho: 70-113.

CMN 1942a. Acervo documental da Mina da Folgadoura. Porto: Circunscrição Mineira do Norte, Departamento de Recursos Geológicos do Ministério da Economia.
CMN 1956b. Acervo documental da Mina do Folgadoiro Porto: Circunscrição Mineira do Norte, Departamento de Recursos Geológicos do Ministério da Economia.

Comendador, B. 1999. Cambios de escala de producción metalúrgica durante las fases finales de la Edad del Bronce. Actas do Congresso de Proto-História Europeia, Guimarães 1999. Vol. II. Revista de Guimarães - Volume especial. Guimarães: Sociedade Martins Sarmento: 515-538.

FERNANDES, M.G. 1992. Viana do Castelo: obras públicas e evolução do espaço urbano (1855-1926). Revista da Faculdade de Letras - Geografia 8. Série I: 65-162.

HARBISON, P. 1967. Mediterranean and antlantic elements in the Early Bronze Age of Northern Portugal and Galicia. Madrider Mitteilungen 8: 100-122.

IGEOE 1997. Carta Militar de Portugal na escala 1:25 000, Folha 40 (Viana do Castelo). Série M 888. Lisboa: Instituto Geográfico do Exército.

LIMA, M.F.D.L. 2006. Caracterização e estratégias de valorização sustentável de ocorrências geológicas com importância patrimonial. Braga: Universidade do Minho (Tese de Doutoramento)

MACWHITE, E. 1951. Estudios sobre las relaciones atlánticas en la Península Ibérica en la Edad del Bronce. Madrid: Publicaciones del Seminario de Historia Primitiva del Hombre, Disertaciones Matritenses 2.

Pereira, E. (coord.) 1989. Carta Geológica de Portugal, na escala de 1:200 000, Folha 1. Lisboa: Serviços Geológicos de Portugal.

Pereira, E. (coord.) 1992. Carta Geológica de Portugal, na escala 1:200 000. Notícia Explicativa da Folha 1. Lisboa: Serviços Geológicos de Portugal.

Russell CORTEZ, F. 1946. Machados e outros objectos de bronze. Porto: Museu Nacional de Soares dos Reis.

VILAÇA, R. 2007. Depósitos de bronze do território português. Um debate em aberto, Coimbra: Faculdade de Letras da Universidade de Coimbra.

ZBYSZEWSKI, G. \& FERREIRA, O.V. 1955. Sur un plaque anthropomorphe en cuivre dans la mine d'étain de "Folgadoura". Comunicações dos Serviços Geológicos de Portugal 36: 49-50 . 